\title{
Clinical therapeutic guideline for neurorestoration in spinal cord injury (Chinese version 2016)
}

This article was published in the following Dove Press journal:

Journal of Neurorestoratology

3 April 2017

Number of times this article has been viewed

\section{Yaping Feng ${ }^{1, *}$ \\ Tiansheng Sun ${ }^{2, *}$ \\ Lin Chen ${ }^{3}$ \\ Jiaxin Xie \\ Zhicheng Zhang ${ }^{2}$ \\ Hongyun Huang ${ }^{4}$ \\ Xijing $\mathrm{He}^{5}$ \\ On behalf of the \\ Chinese Association of Neurorestoratology and \\ Chinese Branch of the International Association of Neurorestoratology \\ 'Department of Neurosurgery, Kunming General Hospital of People's Liberation Army (Spinal Cord Injury Treatment Center of People's Liberation Army), Kunming, Yunnan, ${ }^{2}$ Department of Orthopedics, Beijing Army General Hospital, ${ }^{3}$ Department of Neurosurgery, Yuquan Hospital, Tsinghua University, ${ }^{4}$ Institute of Neurorestoratology, General Hospital of Armed Police Forces, Beijing, ${ }^{5}$ Department of Orthopedics, The Second Affiliated Hospital of Xi'an Jiaotong University, Xi'an, Shaaxi, China \\ *These authors contributed equally to this work}

Correspondence: Xijing He Department of Orthopedics, The Second Affiliated Hospital of Xi'an Jiaotong University, 157 West Road, 710004 Xi'an, Shaanxi, China Tel +86 I390926 6195

Email xijing_h@vip.tom.com

Hongyun Huang

Institute of Neurorestoratology, General Hospital of Armed Police Forces, No. 69 Yongding Road, 100039 Beijing, China

Tel +86 I39 I0II 6608

Email hongyunh@gmail.com
Abstract: Restoring functions following spinal cord injury (SCI) was the most challenging task in clinical practice in the past. Fortunately, some effective neurorestorative methods have been exploited in acute, subacute, and chronic phase of SCI. There were no clinical neurorestorative therapeutic guidelines available before this document which can be followed by physicians to manage patients with acute, subacute, and chronic SCI. This guideline will be a helpful reference to physicians to implement their neurorestorative strategies that can help to improve the neurological functions in patients with SCI and their quality of life.

Keywords: clinical therapeutic guideline, neurorestorative strategies, spinal cord injury, cell therapy, cordotomy, neurotization

\section{Introduction}

Spinal cord injury (SCI) refers to insult of the spinal cord or cauda equina caused by fracture or dislocation of the vertebrae, with or without an open wound track. Approximately $14 \%$ of spinal fracture victims suffer from SCI. SCI often occurs among people aged 30-40 years old. In recent years, the mortality rate of spine injury and SCI has reduced from $4.42 \%$ to $0.44 \%$ due to the progress of prehospital first aid, treatments in acute stage, and nursing techniques, resulting in improved quality of life of the patients, and most of the patients now show only little difference in life span compared with common people. There are more than one million patients with spine injury and SCI in China, and the number is still growing with 120,000 cases per year. ${ }^{1-6}$

Restoring function in people with SCI is one of the most challenging tasks in clinical practice. Recently, neurorestorative strategies have been translated to clinical practice, and patients have benefited and their quality of life has improved. ${ }^{7}$ The following clinical neurorestorative guideline focuses on therapeutic methods that can be used in acute, subacute, and chronic phase. This document is based on scientific and professional information available before the May of 2016, which is concerned with the latest clinical advances and the reasonable evidences available for efficacy of SCI treatments.

This guideline is recommended to the Chinese and global medical/scientific communities for clinical treatment and further research on the SCI. We especially emphasize that although the methods listed in this guideline can restore some functions in SCI patients to some extent, they may not benefit those with higher expectation. 


\section{Acute and subacute phase Evaluation \\ Physical examinations}

The neurological examinations that are performed 1-2 days after injury are not reliable; therefore, comprehensive neurological examinations should be done 3 days after injury to assess its severity and to estimate the possible outcomes of treatment. It must be emphasized that about one-fourth of the cervical spinal cord-injured patients may also suffer from head injury, while thoraco-lumbar SCI may also be accompanied by chest injury, abdominal injury, pelvic injury, and limb injury, and thus, complete physical examinations are critically necessary to avoid misdiagnosis. ${ }^{3,8,9}$

The most commonly used quantitative diagnostic method is the American Spinal Injury Association (ASIA) neurological score (Figure 1), which includes motor, pinprick, and touch scores. The ASIA motor scores (100 points) are obtained by grading ten muscle groups on each side of the body, and each muscle is scored on a scale of $0-5$ ( $0=$ no voluntary movement, $1=$ slight movement, $2=$ definite movement, $3=$ movement against gravity, $4=$ movement against manual resistance, $5=$ normal). Pinprick and touch sensations are separately scored on a scale of $0-2$ in each dermatome, and then the scores are summed to obtain 56-point sensory scores for each side of the body, adding up to a total of 112 points. ${ }^{10}$

The International Association of Neurorestoratology SCI Functional Rating Scale (IANR-SCIFRS) (Table 1) can be utilized to assess the daily-life functional capacities of spinal cord-injured patients. ${ }^{11}$

\section{Accessory examinations}

\section{$X$-ray plain film}

The film includes frontal, lateral examination; however, the lateral film should be examined first to avoid moving the patient much. Sometimes, a double oblique examination should be performed. The main aspects of observation should include alignment of the vertebrae, type of fracture or dislocation, appendix of vertebra fracture, and intervertebral space narrowing or broadening.

\section{Computed tomography (CT)}

Axial and three-dimensional CT scans could reveal the shape of spinal canal and vertebral facet joints. For combined injuries, CT scan should be performed.

\section{Magnetic resonance imaging (MRI)}

MRI is the preferred examination for SCI patients, by which the location, severity, and extent of the injury of the cord can be observed clearly. Usually, the damaged disc and ligament or its displaced debris in the canal can be observed through MRI.

\section{Somatosensory evoked potential (SEP)}

When SCI occurs, SEP examination can be performed for checking the function and integrity of the cord. If SEP cannot be detected 24 hours after injury, and there were no signs of regaining observed through continuous examinations for several weeks, the injury of the spinal cord must be complete; otherwise, the injury is incomplete. However, the SEP examination could only test the sensory function, and not the locomotor function.

\section{Diagnosis}

The SCI diagnosis should include the level and severity of the injury of the spinal cord, the level and type of fracture or/and dislocation of the injured vertebrae, and the stability of the spinal column. The severity of the SCI is classified according to the ASIA Impairment Scale. ${ }^{10}$ An injury is assigned ASIA grade $A$ if both perianal sensation and voluntary anal sphincter contraction are absent. ASIA grade B indicates that some sensation is preserved but motor score is zero below the injury level. ASIA grade $\mathrm{C}$ indicates that some motor function is present but motor scores below the injury level add up to less than $50 \%$ of normal. ASIA grade D indicates that motor scores below the injury level add up to $50 \%$ or greater than normal.

\section{Treatments}

The SCI therapeutic outcome partly depends on the number of surviving axons - the more the number of surviving axons, the more the neurological functions might be restored. Therefore, SCI therapy is critical as it alleviates the secondary acute or subacute SCI. The principles of SCI treatments include early reduction and fixation, combined extramedullary and intramedullary decompression, cell transplantation, early rehabilitation treatment, and complication prevention. ${ }^{3,8,9,12,13}$

\section{Prehospital first aid}

About $25 \%$ of the neurological function impairment following spine injury is caused by improper handling; thus, first-aid management for SCI patients should be taken more seriously. The optimal way to handle an SCI patient is that three or more people from both sides or one side should lift the patient horizontally and place him/her on a flat board or a special stretcher, for transporting to specialized hospital by ambulance or helicopter. ${ }^{3}$ 


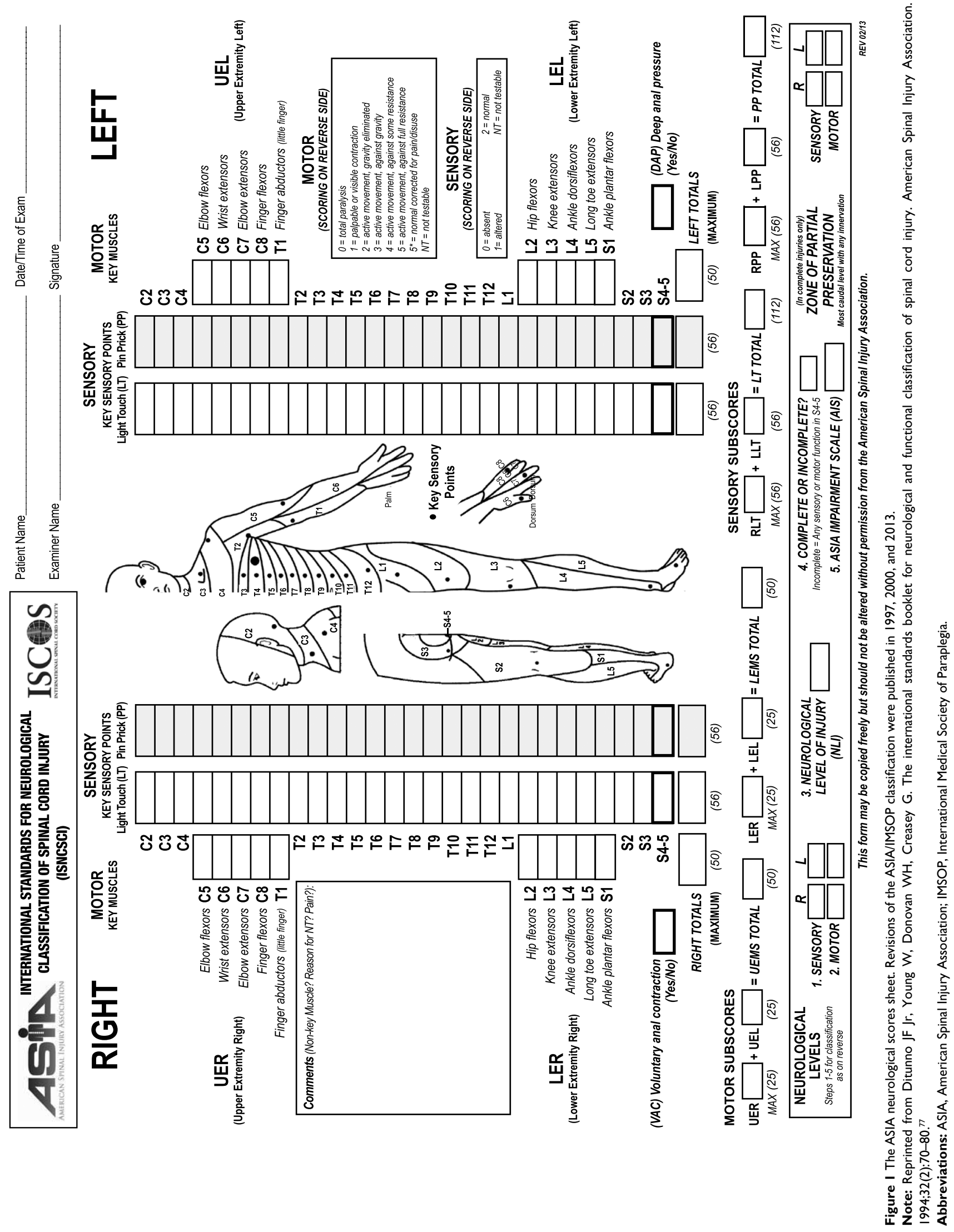


Table I International Association of Neurorestoratology Spinal Cord Injury Functional Rating Scale
I. Upper limb movement
(I) Eating and drinking
3 Normal
2 Finish independently with difficulty
I Some assistance
0 Total dependence
(2) Grooming
3 Normal
2 Finish independently with difficulty
I Some assistance
0 Total dependence
(3) Writing
3 Normal
2 Slow or sloppy; most words legible
I Many words not legible
0 Unable to grip pen
2. Lower limb movement
(4) Standing without brace
3 Normal
2 Stand independently but unsteady
I Some assistance
0 Cannot do
(5) Walking without brace
3 Normal
2 Walk independently but slow or unsteady
I Some assistance
0 Cannot do

\section{Trunk movement}
(6) Sitting
3 Normal
2 Stable when still, but unstable when moving
I Unstable when still
0 Cannot do
(7) Turning body over
3 Normal
2 Finish independently with difficulty
I Some assistance

\section{(I0) Dressing}
3 Normal
2 Finish independently with difficulty
I Some assistance
0 Total dependence
5. Sphincter control
(I I) Bladder control
3 Normal
2 Reflex voiding with partial sensation or control
I Reflex voiding without sensation or control
0 Total incontinence or urethral catheterization/cystostomy needed
(12) Bowel control
3 Normal
2 Partial control with sensation
I Partial control without sensation or no control with partial sensation
0 Total incontinence
6. (13) Muscular tension (refers to the amount of tension or resistance
to movement in a muscle)
3 Normal
2 Slight increase/decrease or mild spasm
I Large increase/decrease or significant spasm
0 Extreme stiffness or spasticity

\section{7. (14) Sweating}
3 Normal
2 Slight decrease
I Significant decrease
0 Absent sweating
8. (I5) Skin condition
3 Normal
2 Partial breakdown
I Significant breakdown, often associated with edema
0 Enduring bedsore or skin damage; severe edema

\section{9. (16) Pain}
3 No pain
2 Mild pain, ordinary pain killer effective
I Severe pain, narcotics required
0 Extreme pain, uncontrolled

0 Total dependence

4. General movement

(8) Transfers: bed to chair/wheelchair

3 Normal

2 Finish independently with difficulty

I Some assistance

0 Total dependence

(9) Bathing

3 Normal

2 Finish independently with difficulty

I Some assistance

0 Total dependence

Notes: This scale includes nine categories with 16 items in total (plus one optional category). The maximum possible score is 48 ; the lowest possible score is 0 . Explanation of the functional rating scale scores: 48: normal functioning across all categories; 35-47: slight degree of functional handicap (mostly independent); $18-34$ : medium degree of functional handicap (some dependency indicated); 0-17: severe degree of functional handicap (significant impact on daily life).

\section{Pharmacologic therapy}

Neuroprotection is essential which aims at minimizing and even preventing secondary medullary lesion extension through medical measures which prevent apoptosis and cellular death, and promote neural survival.
I0. (I7) Sexual function (rate for males only; do not include in overall score)

3 Normal

2 Can achieve erection and sexual penetration, but problems with sensation or ejaculation

I Can achieve erection, but no sexual penetration, sensation or ejaculation 0 Unable to achieve erection

\section{Corticosteroid}

High-dose methylprednisolone (MP) therapy at early stage was once considered to be positive for neurological restoration in acute phase of SCI. ${ }^{14-16}$ The results of the National SCI Study (NASCIS I and II) carried out in human were 
modest, with possible severe complications. MP intravenous injection, in the course of 8 hours after the SCI (preferably in the first 3 hours), of a $30 \mathrm{mg} / \mathrm{kg}$ bolus followed by a continuous injection of $5.4 \mathrm{mg} / \mathrm{kg}$ hourly, for the next 23 hours, demonstrates certain efficiency. So far, no undeniable proof supports its routine application. In fact, the American Association of Neurological Surgeon and the Congress of Neurological Neurosurgeons concluded in March 2002 that MP use in SCI for 24-48 hours is recommended as an option. Latest research revealed that there was not enough medical evidence supporting that high-dose MP certainly improves neurological restoration in acute SCI; however, complications such as infection, respiratory impairment, gastrointestinal bleeding, and even death can happen more likely in patients who undergo high-dose MP therapy. Hence, high-dose MP therapy has no longer been used routinely in acute SCI, but it is still an optional therapeutic method. ${ }^{17-19}$

MP can still be used in incomplete cervical medullary lesions, and especially in patients with a cervical spondylitis myelopathy which requires a decompression, but caution should be paid on the following factors: (a) Time window (less than 8 hours): infusion speed should be controlled strictly in the application of high-dose MP with accurate measurement of body weight and dose. ${ }^{20} \mathrm{MP}$ should be given as a bolus dose of $30 \mathrm{mg} / \mathrm{kg}$ over 15 minutes, followed by a continuous 23 -hour infusion of $5.4 \mathrm{mg} / \mathrm{kg} /$ hour. (b) Administration of MP should be stopped as soon as possible for patients whose prior neurologic symptoms have resolved to reduce deleterious side effects. (c) Contraindications for high-dose MP treatment include spinal injury without neurological deficits, penetrating and gunshot injury of spinal cord, gastrointestinal bleeding, and diabetes; also, this treatment should not be given up to 8 hours after injury, and in older patients at a higher risk of pneumonia.

\section{GM-I (ganglioside)}

There is not enough clinical evidence supporting that GM-1 certainly improves neurological restoration and lowers mortality in acute SCI; therefore, GM-1 is not recommended for routine use in acute $\mathrm{SCI} .{ }^{17,21}$

\section{Other medicines}

Erythropoietin (EPO) has glioprotective and neuroprotective properties, which reduces medullary cavitation, cellular infiltration, and neuronal apoptosis. The use of human EPO following spinal cord injury, by injecting a dose of 5000 units $/ \mathrm{kg}$ through either a single intraperitoneal injection or a daily injection over a period of 7 days, has beneficial effects on the neurological recovery. However, no definite conclusion has been drawn due to the insufficient number of the subgroups of patients. In addition, clinical trials of minocycline, naloxone, and tirilazad have shown limited therapeutic effects on patients with SCI. Mannitol could alleviate secondary spinal cord edema, which supports its early application in the absence of contraindications. ${ }^{22}$

\section{Local hypothermia treatment}

Local hypothermia treatment can decrease the metabolism of the injury site, reducing oxygen consumption, which could be performed in an open or a closed environment through an epidural or subdural coolant lavage $\left(6^{\circ} \mathrm{C}\right)^{23}$ or an intravascular route $\left(\right.$ at $\left.34^{\circ} \mathrm{C}\right) .^{24}$

\section{Surgical management \\ Early decompression and stabilization}

Rebuilding the stability of the spinal column with reduction and fixation of the vertebrae could restore the volume of the spinal canal with laminoplasty or laminectomy. Acute SCI with spine alignment restoration and stabilization (within 24 hours) can be performed safely, which is associated with improved neurological outcome, shorter hospitalization time, and less complications. Decompression of the spinal cord after acute SCI attenuates secondary injury, preserving neurological functions of the survived axons and preventing further spinal cord tissue destruction.

\section{Time window of surgery}

According to massive clinical researches and specialist investigations, the decompression operation and internal fixation should be performed as soon as possible (less than 24 hours) in the absence of life-threatening complications in patients with obvious neurologic deficit, no matter the injury is complete (ASIA A) or incomplete (ASIA B-D). ${ }^{25-30}$ However, in the actual situation, there are a few patients who undergo operation within 24 hours due to transportation, preoperative examinations, and preparations. A largest clinical study of almost $5000 \mathrm{SCI}$ patients who underwent early surgical interventions (less than 3 days) showed that earlier surgical treatment appeared to provide better effect., ${ }^{3,31}$

\section{Cordotomy or myelotomy}

Decompression of the extradural elements is the primary focus in the management of patients with acute SCI. Little attention has been given to the potential deleterious secondary injury from spinal cord necrosis and hemorrhage. Following SCI, the resulting spinal cord swelling and any sustained external pressure may block normal cerebrospinal fluid flow and further increase spinal cord edema. Myelotomy and 
early debridement of necrosis may be beneficial in preventing complete paralysis by stopping further expansion of secondary injury, reducing the pressure of spared tissue and cerebrospinal fluids, preserving survived axons and spared spinal cord tissue, delaying the glial cell death in white matter, and providing conduction basis for neurological recovery.

Some data have showed that decompression of dura may limit the level of secondary injury in human and animal SCI. Clinical studies have reported the neurological improvement in acute SCI patients with myelotomy. ${ }^{3,12,31,32}$ However, prospective randomized clinical trials are still lacking.

\section{Injury type and decompressed procedure}

Since complete transection of the spinal cord is quite rare in clinic, intramedullary decompression should be performed under microscope, while combining with findings of CT and MRI, to preserve survived axons in neurologically impaired patients. Here are four types of surgical interventions for injured spinal cord and their effects:

(a) Arachnoid adhesion, fluctuation disappearance of spinal cord, obstruction of cerebrospinal fluid (CSF), and pale and swollen spinal cord. Intervention: releasing adhesion of the arachnoid, restoring the CSF flow, and pulsation of the cord.

(b) Intramedullary hematoma, bony fragments, or foreign matter. Intervention: removing hematoma, bony fragments, or foreign matter and exploring the cord.

(c) The spinal cord is partly disrupted. Liquefied tissues might gush out as soon as the dura mater is opened. Intervention: exploring the injury site, removing the necrotic tissues, and washing the region gently with normal saline.

(d) Intramedullary softening region is found. Intervention: making a $0.3-0.5 \mathrm{~cm}$ longitudinal incision at the softening region, removing the softening tissue, and washing the cavity gently with normal saline.

Since the border between contusion and normal spinal cord is not clear at early stage, the range of the intramedullary decompression should not be extended too much.

\section{Neurophysiological assessment}

Intraoperative neurophysiological evaluation of acute or subacute SCI patients can provide information about spinal cord function that is not retrievable by other clinical methods and can correctly predict neurological outcome.

\section{Cell therapy}

Cell therapy is a promising therapeutic option for acute and subacute SCI. There are a few clinical trials of cell therapy for acute or subacute SCI, with ${ }^{33}$ or without positive outcome. ${ }^{34}$ An acute SCI leads to obvious edema and inflammatory reaction in damaged area, and cell injections may exacerbate injury at this period; so, the spinal cord with an acute injury may not be suitable for direct cell transplantation into injured area.

The mechanisms of cell therapies for SCI include axonal remyelination and regeneration, neuroplasticity, neuroprotection, neuromodulation, neurorepair, anti-inflammatory response, neurogenesis, angiogenesis, reducing scar and cavity formation, and cell replacement. ${ }^{22}$

\section{Electrical stimulation therapy}

The neurologic system relies on biological electricity for information transfer, and local electric stimulation may improve and induce nerve axon regrowth. ${ }^{35}$

\section{Rehabilitation therapy}

Passive rehabilitation therapy

Postoperatively, passive rehabilitation therapy such as massage and pressure therapy can not only reduce incidence of pressure sore and deep venous thrombosis but also restore neurological functions.

\section{Positive rehabilitation therapy}

As soon as patient's condition allows to do exercise after surgery, he/she with the assistance of a halo or vest can begin positive rehabilitation therapy such as occupational training, locomotion training, and hydrotherapy. The recommended positive training method is active movement-target enhancement-neurorehabilitation therapy, which can help patients to maximize functional neurorestoration. ${ }^{11}$

\section{Others}

Acupuncture $^{36}$ and laser puncture ${ }^{37}$ may promote functional recovery for patients with acute or subacute SCI with rare risks.

\section{Complications and managements Circulatory complications Hypopiesis}

After cervical SCI, activities of sympathetic nerves are suppressed, while parasympathetic nerves are not affected; as a result, the patient would have more sputum, slower heart rate, and decreased blood pressure. At this point, anisodamine could be applied through intravenous drip ( $20 \mathrm{mg}$ added into $500 \mathrm{ml}$ normal saline) at a speed of 11-15 drops per minute for an adult, while the speed should be modified according to 
body surface area for a child. The symptoms usually would be improved including increased heart rates and mean arterial pressure, and reduced sputum.

\section{Hyponatremia}

Hyponatremia is a common and severe complication after cervical SCI with an incidence of $45-100 \%$. Hyponatremia often occurs at 6.4-8.9 days postinjury, and the lowest serum sodium concentration is detected at 8.7-17.3 days after injury, while serum sodium concentration begins to rise at $21.8 \pm 10.2$ days after the lowest level. In general, hyponatremia would disappear after $30.4 \pm 6.0$ days. Factors related to hyponatremia are level of cervical SCI, infections, use of ventilator, and medications (such as dehydrating agent and diuretic). At this point, refined carbamide could be used (oral administration, $30 \mathrm{mg} /$ day) for inappropriate antidiuretic hormone syndrome, while fludrocortisone could be used (oral administration, $0.1-0.2 \mathrm{mg} /$ day) for cerebral salt wasting syndrome. However, these two types of syndromes are difficult to distinguish, and fludrocortisone (added into normal saline) is safe and effective for agnogenic hyponatremia.

\section{Deep venous thrombosis (DVT)}

According to statistics, the incidence of DVT with clinical symptom after SCI is about $16.3 \%$, while the incidence of DVT detected by ultrasonography or venography is up to $79 \%$. Preventive measures for DVT include limb exercise and wearing elastic stockings. Once DVT occurs, anticoagulant therapy should be applied. The thrombus may fall off, leading to embolisms of the heart, lung, and brain, and hence, caution is required.

\section{Respiratory complications}

Difficult breathing and pulmonary infection are the main respiratory system complications after spine injury and SCI. Patients with cervical SCI up to C4 level or above might suffer from diaphragm muscular paralysis, and weakened or even disappeared cough reflex, leading to dyspnea and lung infection. At this point, it is necessary to apply tracheotomy, in order to facilitate sputum suction and ventilator support.

\section{Urinary complications}

Urinary tract infection is the main complication of urinary system after spine injury and SCI. It is critical to use urinary catheter, and to change the catheter every week, as well as performing bladder washing at regular intervals in order to avoid hydronephrosis and renal failure.

\section{Chronic phase}

\section{Evaluation}

Physical examinations

Neurological functions can be assessed by ASIA, and dailylife functions can be assessed by IANR-SCIFRS.

\section{Magnetic resonance imaging}

MRI can clearly show the current condition of the injured cord, such as atrophy, myelomalacia, cystic cavity, or even a syringomyelia, formatted scar, and cord compression if present.

\section{Electrical physiological examination}

Paravertebral SEP can assess and judge the sensory level of injured cord, and electromyography can assess and judge the motor level of injured section.

\section{Diagnosis}

The chronic SCI diagnosis includes the level and severity of the injury of the spinal cord and judging whether there is still compression in the injured spinal cord.

\section{Treatments}

If patients with chronic SCI still have serious cord compression, decompression might most likely help in neurological functional recovery.

\section{Neurotization or nerve bridging}

Neurotization or nerve bridging can restore some function for patients (aged nearly 50 years) having complete chronic SCI, ${ }^{38,39}$ especially associated with physical rehabilitation after transferring axons to a deinnervated target. There are mainly three methods.

(a) Taking a peripheral nerve from above the injury site, such as the accessory nerve or intercostal nerve, and bridging it to nerve roots or peripheral nerves for paralyzed muscles below the injury site. ${ }^{40,41}$

(b) Taking the ventral root from lumbar 5 or the sacral 1 segment above the injury site and connecting it to the ventral root of sacral 2 or 3 segments that normally innervate the bladder. ${ }^{42,43}$

(c) Taking a peripheral nerve and inserting the central stumps 4-5 $\mathrm{mm}$ into the ventral-lateral bundles of the thoracic cord (the corticospinal tract) just above the complete cord lesion and the distal stump of the grafts connecting to the muscle nerve of the lower limb. ${ }^{44,45}$ 


\section{Neurostimulation/neuromodulation and neuroprosthesis}

Task-specific training with epidural stimulation might reactivate previously silent spared neural circuits or promote plasticity. These interventions could be a viable clinical approach for functional recovery for patients with complete chronic SCI. ${ }^{46-48}$ Transcranial direct current stimulation can be effective in the management of neuropathic pain following chronic SCI. ${ }^{49,50}$ Functional electrical stimulation of permanently deinnervated muscle in patients with complete chronic lower motor neuron lesions is an effective therapy, which results in rescue of muscle mass, function, and perfusion. Additional benefits are improved leg cosmetic appearance and enhanced cushioning effect for seating. ${ }^{51,52}$

Brain-machine interfaces with neuroprosthetic limbs could help patients with long-term paralysis to perform several of the required activities of daily living. ${ }^{53-55}$ Sensory afferentation, feedback input, and related cerebral voluntary motor commands - the latter by electroencephalographybrain computer interface - may thus contribute to wireless informational powering of the respective robotic suit engine for bionic standing and gait assistance. Recently, a study showed that muscle activation could be controlled by using intracortically recorded signals in a paralyzed human. ${ }^{56}$

\section{Cell therapy}

Cell therapy has become an important therapeutic option for chronic SCI. ${ }^{57}$ Increasing clinical evidence suggests that cell therapy is safe and feasible, while several types of cells have been confirmed suitable for transplantation in human, such as olfactory ensheathing cells, Schwann cells, mesenchymal stromal cells, peripheral blood mononuclear cells, bone marrow hematopoietic stem cells, umbilical cord blood mononuclear cells, and bone marrow mononuclear cells. Partial functions and the quality of life have been improved following transplantation of cells into cord parenchyma, intrathecal administration of cells (lesion area or lumbar subarachnoid space), intravascular infusion of cells, and by multiple routes of administration..$^{11,58-68}$ Increasing studies have showed that extracellular vesicles such as exosomes have recently been suggested to mediate neurorestorative effects, ${ }^{69-71}$ and may offer a possible alternative therapeutic strategy for SCI in future.

\section{Techniques of surgery for cell transplantation}

Most cell transplantations for SCI are delivered directly into the site of or adjacent injury by injecting less than $30 \mu \mathrm{L}$ of cell suspension via fine needles or glass capillaries. Several attempts have been made to deliver substrates around the injured cord via intrathecal injection. Intramedullary transplanted cells seem to be optimal for transplantation, which can directly interact with the host environment to activate or trigger dysfunctional neurons or axons, help axons to regenerate and sprout, remyelinate axons, and replace some kind of lost cells. However, inappropriate cellular injections can be damaging, which induce technical failure with false results and conclusion. Risks of intrarparechymal injections include additional injury due to needle penetration, spinal cord motion during injection, creation of intraparenchymal pressure gradients and hydrodynamic dissection, and possible cord ischemia. Understanding these variables can maximize the safety of injections and avoid injury to spared structure. ${ }^{23}$

\section{Clinical requirements}

The following are the clinical requirements: (a) decreasing needle trauma: fewer injections would be optimal, especially in cervical and T11-L1 segment, and incomplete SCI; (b) decreasing time of operation: 2 hours is the golden time for cell transferring from the lab to finish transplant; (c) decreasing size of incision will shorten the time of recovery after surgery; so, minimally invasive operation is required; (d) decreasing total volume of injection: limited thin needle for the higher concentration. ${ }^{22}$

\section{Neurorehabilitation}

Intensive exercise and biofeedback training can improve motor functions for patients with chronic incomplete SCI. ${ }^{72-74}$ Intensive training refers to 6-hours-per-day for 6-days-a-week over-ground locomotion. While the beneficial effects of intensive exercise alone are limited in people with chronic SCI, many investigators believe that such exercise may be essential for motor recovery in people who have received restorative therapies. A phenomenon called "learned non-use" occurs after central nervous system injuries, and intensive, repetitive exercise can reverse atrophy of muscle and nervous tissues. Substantial recovery of function (two ASIA grades) is possible in a patient with severe C-2 ASIA grade A injury by "activity-based recovery". Multimodal intensive exercise can significantly improve motor function in subjects with chronic complete SCI, which might have therapeutic value for these patients as an adjunct to other restorative therapies. An individual with chronic SCI ASIA grade A improved his over-ground walking ability following intensive physical therapy and robotic locomotor training. Yet, these studies were performed with small sample sizes, and so more studies are necessary. 


\section{Combination therapies}

The degree of clinical neurological recovery by a single neurorestorative therapy is still limited. Preliminary results of combination therapies for complete chronic SCI are promising for more functional recovery, which include identical cell transplantation by two or more routes, two or three appropriate kinds of cells being transplanted in synergy, cell therapy with neurorehabilitation, cell therapy with laser puncture, and neurorehabilitation. ${ }^{11,37,75,76}$ Combination therapy studies pose major challenges in terms of logistics and design.

\section{Conclusion}

This guideline will be a helpful reference to physicians to implement their neurorestorative strategies that can help to improve the neurological functions in patients with SCI and their quality of life.

\section{Disclosure}

The authors report no conflicts of interest in this work.

\section{References}

1. Jazayeri SB, Beygi S, Shokraneh F, Hagen EM, Rahimi-Movaghar $\mathrm{V}$. Incidence of traumatic spinal cord injury worldwide: a systematic review. Eur Spine J. 2015;24(5):905-918.

2. Sun T. Present status and prospect of spinal cord injury in China. Chin J Spine Spinal Cord. 2014;24(12):1057-1059.

3. Feng Y, Zhang W, Feng Y, et al. Early comprehensive treatment strategy for acute spinal cord injury. Chin J Neurosurg Dis Res. 2014;13(5):385-388.

4. Specialized Committee of Spine and Spinal Cord Injury; Chinese Society of Rehabilitation Medicine. Expert consensus on evaluation and treatment of early lower cervical spine and spinal cord injury. Chin J Spine Spinal Cord. 2015;25(4):378-384.

5. Specialized Committee of Spine and Spinal Cord Injury; Chinese Society of Rehabilitation Medicine. Expert consensus on evaluation and treatment of early thoracolumbar spine and spinal cord injury. Chin J Spine Spinal Cord. 2011;21(11):963-968.

6. Xu S, Guo S. Basic and Clinical Medicine of Spinal Cord Injury. Beijing: People's Medical Publishing House; 2012.

7. Huang H, Sun T, Chen L, et al. Consensus of clinical neurorestorative progress in patients with complete chronic spinal cord injury. Cell Transplant. 2014;23(Suppl 1):S5-S17.

8. Stein DM, Sheth KN. Management of acute spinal cord injury. Continuum (Minneap Minn). 2015;21(1 Spinal Cord Disorders): 159-187.

9. Ropper AE, Neal MT, Theodore N. Acute management of traumatic cervical spinal cord injury. Pract Neurol. 2015;15(4):266-272.

10. Kirshblum SC, Burns SP, Biering-Sorensen F, et al. International standards for neurological classification of spinal cord injury (revised 2011). J Spinal Cord Med. 2011;34(6):535-546.

11. Huang H, Xi H, Chen L, Zhang F, Liu Y. Long-term outcome of olfactory ensheathing cell therapy for patients with complete chronic spinal cord injury. Cell Transplant. 2012;21(Suppl 1):S23-S31.

12. Zhu H, Feng YP, Young W, et al. Early neurosurgical intervention of spinal cord contusion: an analysis of 30 cases. Chin Med J (Engl). 2008;121(24): 2473-2478.
13. Yilmaz T, Kaptanoglu E. Current and future medical therapeutic strategies for the functional repair of spinal cord injury. World J Orthop. 2015;6(1):42-55.

14. Bracken MB, Shepard MJ, Collins WF, et al. A randomized, controlled trial of methylprednisolone or naloxone in the treatment of acute spinalcord injury. Results of the Second National Acute Spinal Cord Injury Study. N Engl J Med. 1990;322(20):1405-1411.

15. Bracken MB, Shepard MJ, Holford TR, et al. Administration of methylprednisolone for 24 or 48 hours or tirilazad mesylate for 48 hours in the treatment of acute spinal cord injury. Results of the Third National Acute Spinal Cord Injury randomized controlled trial. National Acute Spinal Cord Injury Study. JAMA. 1997;277(20):1597-1604.

16. Bracken MB, Shepard MJ, Holford TR, et al. Methylprednisolone or tirilazad mesylate administration after acute spinal cord injury: 1-year follow up. Results of the Third National Acute Spinal Cord Injury randomized controlled trial. J Neurosurg. 1998;89(5):699-706.

17. Hurlbert RJ, Hadley MN, Walters BC, et al. Pharmacological therapy for acute spinal cord injury. Neurosurgery. 2015;72(Suppl 2):93-105.

18. Evaniew N, Noonan VK, Fallah N, et al; RHSCIR Network. Methylprednisolone for the treatment of patients with acute spinal cord injuries: a propensity score-matched cohort study from a Canadian multi-center spinal cord injury registry. $J$ Neurotrauma. 2015;32(21):1674-1683.

19. Bracken MB. Steroids for acute spinal cord injury. Cochrane Database Syst Rev. 2012;1:CD001046.

20. Bauchet L, Lonjon N, Perrin FE, Gilbert C, Privat A, Fattal C. Strategies for spinal cord repair after injury: a review of the literature and information. Ann Phys Rehabil Med. 2009;52(4):330-351.

21. Chinnock P, Roberts I. Gangliosides for acute spinal cord injury. Cochrane Database Syst Rev. 2005;2(2):85-86.

22. Huang H, Raisman G, Sanberg PR, Sharma H, Chen L. Neurorestoratology. New York: Nova Biomedical; 2015.

23. Hansebout RR, Hansebout CR. Local cooling for traumatic spinal cord injury: outcomes in 20 patients and review of the literature. J Neurosurg Spine. 2014;20(5):550-561.

24. Dididze M, Green BA, Dietrich WD, Vanni S, Wang MY, Levi AD. Systemic hypothermia in acute cervical spinal cord injury: a casecontrolled study. Spinal Cord. 2013;51(5):395-400.

25. Fehlings MG, Rabin D, Sears W, Cadotte DW, Aarabi B. Current practice in the timing of surgical intervention in spinal cord injury. Spine (Phila Pa 1976). 2010;35(21 Suppl):S166-S173.

26. Fehlings MG, Vaccaro A, Wilson JR, et al. Early versus delayed decompression for traumatic cervical spinal cord injury: results of the Surgical Timing in Acute Spinal Cord Injury Study (STASCIS). PLoS One. 2012;7(2):e32037.

27. Wilson JR, Singh A, Craven C, et al. Early versus late surgery for traumatic spinal cord injury: the results of a prospective Canadian cohort study. Spinal Cord. 2012;50(11):840-843.

28. van Middendorp JJ, Hosman AJ, Doi SA. The effects of the timing of spinal surgery after traumatic spinal cord injury: a systematic review and meta-analysis. J Neurotrauma. 2013;30(21):1781-1794.

29. Liu JM, Long XH, Zhou Y, Peng HW, Liu ZL, Huang SH. Is urgent decompression superior to delayed surgery for traumatic spinal cord injury? A meta-analysis. World Neurosurg. 2016;87:124-131.

30. Yue JK, Upadhyayula PS, Chan AK, et al. A review and update on the current and emerging clinical trials for the acute management of cervical spine and spinal cord injuries - Part III. J Neurosurg Sci. 2016;60(4):529-542.

31. Feng Y, Zhu H, Liu Y. Enhancing training of spinal sub specialty in neurosurgery, improving the level of neuro-spine. Chin J Neurosurg Dis Res. 2011;10(3):193-196.

32. Tachibana S, Okada K, Ohwada T, et al. [Posterior longitudinal myelotomy as a surgical treatment of acute cervical spinal cord injury] No Shinkei Geka. 1984;12(2):183-188. Japanese.

33. Yousefifard M, Rahimi-Movaghar V, Nasirinezhad F, et al. Neural stem/progenitor cell transplantation for spinal cord injury treatment; a systematic review and meta-analysis. Neuroscience. 2016;322:377-397. 
34. Lammertse DP, Jones LA, Charlifue SB, et al. Autologous incubated macrophage therapy in acute, complete spinal cord injury: results of the phase 2 randomized controlled multicenter trial. Spinal Cord. 2012;50(9):661-671.

35. McDonald JW, Becker D. Spinal cord injury: promising interventions and realistic goals. Am J Phys Med Rehabil. 2003;82(10 Suppl): S38-S49.

36. Wong AMK, Leong CP, Su TY, Yu SW, Tsai WC, Chen CP. Clinical trial of acupuncture for patients with spinal cord injuries. Am J Phys Med Rehabil. 2003;82(1):21-27.

37. Bohbot A. Olfactory ensheathing glia transplantation combined with LASERPONCTURE(R) in human spinal cord injury: results measured by electromyography monitoring. Cell Transplant. 2010;19(2):179-184.

38. Carlsson CA, Sundin T. Reconstruction of efferent pathways to the urinary bladder in a paraplegic child. Rev Surg. 1967;24(1):73-76.

39. Carlsson CA, Sundin T. Reconstruction of afferent and efferent nervous pathways to the urinary bladder in two paraplegic patients. Spine (Phila Pa 1976). 1980;5(1):37-41.

40. Zhang S, Johnston L, Zhang Z, et al. Restoration of stepping-forward and ambulatory function in patients with paraplegia: rerouting of vascularized intercostal nerves to lumbar nerve roots using selected interfascicular anastomosis. Surg Technol Int. 2003;11:244-248.

41. Lin H, Hou CL, Zhong G, Xie Q, Wang S. Reconstruction of reflex pathways to the atonic bladder after conus medullaris injury: preliminary clinical results. Microsurgery. 2008;28(6):429-435.

42. Xiao CG, Du MX, Dai C, Li B, Nitti VW, de Groat WC. An artificial somatic-central nervous system-autonomic reflex pathway for controllable micturition after spinal cord injury: preliminary results in 15 patients. J Urol. 2003;170(4 Pt 1):1237-1241.

43. Brunelli G, von Wild $\mathrm{K}$. Unsuspected plasticity of single neurons after connection of the corticospinal tract with peripheral nerves in spinal cord lesions. J Korean Neurosurg Soc. 2009;46(1):1-4.

44. von Wild KR, Brunelli GA. Restoration of locomotion in paraplegics with aid of autologous bypass grafts for direct neurotisation of muscles by upper motor neurons--the future: surgery of the spinal cord? Acta Neurochir Suppl. 2003;87:107-112.

45. Yang ML, Li JJ, Zhang SC, et al. Functional restoration of the paralyzed diaphragm in high cervical quadriplegia via phrenic nerve neurotization utilizing the functional spinal accessory nerve. J Neurosurg Spine. 2011;15(2):190-194.

46. Harkema S, Gerasimenko Y, Hodes J, et al. Effect of epidural stimulation of the lumbosacral spinal cord on voluntary movement, standing, and assisted stepping after motor complete paraplegia: a case study. Lancet. 2011;377(9781):1938-1947.

47. Minassian K, Jilge B, Rattay F, et al. Stepping-like movements in humans with complete spinal cord injury induced by epidural stimulation of the lumbar cord: electromyographic study of compound muscle action potentials. Spinal Cord. 2004;42(7):401-416.

48. Young W. Electrical stimulation and motor recovery. Cell Transplant. 2015;24(3):429-446.

49. Fregni F, Boggio PS, Lima MC, et al. A sham-controlled, phase II trial of transcranial direct current stimulation for the treatment of central pain in traumatic spinal cord injury. Pain. 2006;122(1-2):197-209.

50. Soler MD, Kumru H, Pelayo R, et al. Effectiveness of transcranial direct current stimulation and visual illusion on neuropathic pain in spinal cord injury. Brain. 2010;133(9):2565-2577.

51. Kern H, Carraro U, Adami N, et al. Home-based functional electrical stimulation rescues permanently denervated muscles in paraplegic patients with complete lower motor neuron lesion. Neurorehabil Neural Repair. 2010;24(8):709-721.

52. Kern H, Carraro U, Adami N, et al. One year of home-based daily FES in complete lower motor neuron paraplegia: recovery of tetanic contractility drives the structural improvements of denervated muscle. Neurol Res. 2010;32(1):5-12.

53. Wood H. Neural repair and rehabilitation: achieving complex control of a neuroprosthetic arm. Nat Rev Neurol. 2013;9(2):62.
54. Collinger JL, Wodlinger B, Downey JE, et al. High-performance neuroprosthetic control by an individual with tetraplegia. Lancet. 2013;381(9866):557-564.

55. Hochberg LR, Serruya MD, Friehs GM, et al. Neuronal ensemble control of prosthetic devices by a human with tetraplegia. Nature. 2006;442(7099): 164-171.

56. Bouton CE, Shaikhouni A, Annetta NV, et al. Restoring cortical control of functional movement in a human with quadriplegia. Nature. 2016;533(7602):247-250.

57. Young W, AlZoubi Z, Saberi H, et al. Beijing declaration of International Association of Neurorestoratology (IANR). J Neurorestoratol. 2015; 3:121-122.

58. Oraee-Yazdani S, Hafizi M, Atashi A, et al. Co-transplantation of autologous bone marrow mesenchymal stem cells and Schwann cells through cerebral spinal fluid for the treatment of patients with chronic spinal cord injury: safety and possible outcome. Spinal Cord. 2016;54(2):102-109.

59. Li L, Adnan H, Xu B, et al. Effects of transplantation of olfactory ensheathing cells in chronic spinal cord injury: a systematic review and meta-analysis. Eur Spine J. 2015;24(5):919-930.

60. Mendonça MV, Larocca TF, de Freitas Souza BS, et al. Safety and neurological assessments after autologous transplantation of bone marrow mesenchymal stem cells in subjects with chronic spinal cord injury. Stem Cell Res Ther. 2014;5(6):126.

61. Saberi H, Firouzi M, Habibi Z, et al. Safety of intramedullary Schwann cell transplantation for postrehabilitation spinal cord injuries: 2-year follow-up of 33 cases. J Neurosurg Spine. 2011;15(5):515-525.

62. Ra JC, Shin IS, Kim SH, et al. Safety of intravenous infusion of human adipose tissue-derived mesenchymal stem cells in animals and humans. Stem Cells Dev. 2011;20(8):1297-1308.

63. Bhanot Y, Rao S, Ghosh D, Balaraju S, Radhika CR, Satish Kumar KV. Autologous mesenchymal stem cells in chronic spinal cord injury. Br J Neurosurg. 2011;25(4):516-522.

64. Iwatsuki K, Tajima F, Ohnishi YI, et al. A pilot clinical study of olfactory mucosa autograft for chronic complete spinal cord injury. Neurol Med Chir (Tokyo). 2016;56(6):285-292.

65. Tabakow P, Raisman G, Fortuna W, et al. Functional regeneration of supraspinal connections in a patient with transected spinal cord following transplantation of bulbar olfactory ensheathing cells with peripheral nerve bridging. Cell Transplant. 2014;23(12):1631-1655.

66. Zhu H, Poon W, Liu Y, et al. Phase I-II clinical trial assessing safety and efficacy of umbilical cord blood mononuclear cell transplant therapy of chronic complete spinal cord injury. Cell Transplant. Epub 2016 Apr 5.

67. Oh SK, Choi KH, Yoo JY, Kim DY, Kim SJ, Jeon SR. A phase III clinical trial showing limited efficacy of autologous mesenchymal stem cell therapy for spinal cord injury. Neurosurgery. 2016;78(3): 436-447.

68. Wang S, Lu J, Li YA, et al. Autologous olfactory lamina propria transplantation for chronic spinal cord injury: three-year follow-up outcomes from a prospective double-blinded clinical trial. Cell Transplant. 2016;25(1):141-157.

69. Scherf H, Rietschel G. Bemerkenswerte Neunachweise des Auftretens der Dasselfliege Oestromyia leporina (Pallas, 1778) in Deutschland [New noteworthy demonstration of the occurrence of the botfly Oestromyia leporina (Pallas, 1778) in Germany]. Z Parasitenkd. 1967;28(3):223-231. German.

70. Doeppner TR, Herz J, Gorgens A, et al. Extracellular vesicles improve post-stroke neuroregeneration and prevent postischemic immunosuppression. Stem Cells Transl Med. 2015;4(10):1131-1143.

71. Fais S, O'Driscoll L, Borras FE, et al. Evidence-based clinical use of nanoscale extracellular vesicles in nanomedicine. ACS Nano. 2016;10(4):3886-3899.

72. Harness ET, Yozbatiran N, Cramer SC. Effects of intense exercise in chronic spinal cord injury. Spinal Cord. 2008;46(11):733-737.

73. Beekhuizen KS, Field-Fote EC. Sensory stimulation augments the effects of massed practice training in persons with tetraplegia. Arch Phys Med Rehabil. 2008;89(4):602-608. 
74. Moreh E, Meiner Z, Neeb M, Hiller N, Schwartz I. Spinal decompression sickness presenting as partial Brown-Sequard syndrome and treated with robotic-assisted body-weight support treadmill training. J Rehabil Med. 2009;41(1):88-89.

75. Ichim TE, Solano F, Lara F, et al. Feasibility of combination allogeneic stem cell therapy for spinal cord injury: a case report. Int Arch Med. 2010;3:30
76. Rabinovich SS, Seledtsov VI, Poveschenko OV, et al. Transplantation treatment of spinal cord injury patients. Biomed Pharmacother. 2003; 57(9):428-433.

77. Ditunno JF Jr, Young W, Donovan WH, Creasey G. The international standards booklet for neurological and functional classification of spinal cord injury. American Spinal Injury Association. Paraplegia. 1994;32(2):70-80.
Journal of Neurorestoratology

\section{Publish your work in this journal}

The Journal of Neurorestoratology is an international, peer-reviewed, open access online journal publishing original research and review articles on the subject of Neurorestoratology. To provide complete coverage of this revolutionary field the Journal of Neurorestoratology will report on relevant experimental research, technological advances,

\section{Dovepress}

and clinical achievements. The manuscript management system is completely online and includes a very quick and fair peer-review system, which is all easy to use. Visit http://www.dovepress.com/testimonials. php to read real quotes from published authors. 